\title{
Exclusive breast feeding in early infancy reduces the risk of inpatient admission for diarrhea and suspected pneumonia in rural Vietnam: a prospective cohort study
}

\author{
Sarah Hanieh ${ }^{*}$, Tran T. Ha², Julie A. Simpson ${ }^{3}$, Tran T. Thuy ${ }^{2}$, Nguyen C. Khuong ${ }^{4}$, Dang D. Thoang ${ }^{4}$, \\ Thach D. Tran ${ }^{2,5}$, Tran Tuan², Jane Fisher ${ }^{5}$ and Beverley-Ann Biggs ${ }^{1,6}$
}

\begin{abstract}
Background: Acute respiratory infections and diarrhea remain the leading causes of infant morbidity and mortality, with a high burden of both pneunomia and diarrhea in South-East Asia. The aim of the study was to determine antenatal and early infant predictive factors for severe morbidity episodes during the first 6 months of life in Ha Nam province, Vietnam.

Methods: A prospective cohort study of 1049 infants, born to women who had previously participated in a cluster randomized controlled trial of antenatal micronutrient supplementation in rural Vietnam, was undertaken between 28th September 2010 and 8th Jan 2012. Infants were followed until 6 months of age, and the outcome measure was inpatient admission for suspected pneumonia or diarrheal illness during the first 6 months of life. Risk factors were assessed using univariable logistic regression and multiple logistic regression.

Results: Of the 1049 infants seen at 6 months of age, $8.8 \%$ required inpatient admission for suspected pneumonia and $4 \%$ of infants required inpatient admission for diarrheal illness. One third of infants (32.8\%) were exclusively breast fed at 6 weeks of age. Exclusive breast feeding at 6 weeks of age significantly reduced the odds of inpatient admission for suspected pneumomia (Odds Ratio (OR) 0.39, 95 \% Confidence Interval (CI) 0.20 to 0.75) and diarrheal illness (OR 0.37, $95 \% \mathrm{Cl} 0.15$ to 0.88$)$.
\end{abstract}

Conclusions: Exclusive breast feeding in early infancy reduces the risk of severe illness from diarrhea and suspected pneumonia. Public health programs to reduce the burden of inpatient admission from diarrheal and respiratory illness in rural Vietnam should address barriers to exclusive breast feeding.

Keywords: Diarrhea, Suspected pneumonia, Exclusive breast feeding, Inpatient admission

\section{Background}

Globally, pneumonia and diarrheal diseases remain the leading causes of childhood morbidity and mortality and are one of the most common reasons for hospital admission in children in low resource countries [1]. It is estimated that 700000 child deaths result from diarrheal disease, and 156 million childhood clinical pneumonia cases occur annually, resulting in approximately 2 million

\footnotetext{
*Correspondence: shanieh@unimelb.edu.au

'Department of Medicine, University of Melbourne, Doherty Institute, Parkville, VIC 3050, Australia

Full list of author information is available at the end of the article
}

deaths in children during the first 5 years of life [1]. The burden of pneumonia and diarrhea is highest in SouthEast Asia and Africa, with the highest incidence seen in poor and marginalized groups [2]. Recurrent infection and hospitalisation in early life can lead to poor growth and development in childhood, and can impose substantial economic burden on the population and healthcare system. In low income countries, multiple episodes of severe diarrhea in early infancy have been shown to lead to nutritional deficits and long-term growth consequences [3, 4]. The majority of deaths associated with diarrhea and 
pneumonia occur during the first two years of life, which has important implications for health policy $[5,6]$.

In Vietnam, the under-five mortality rate is 23.8 per 1000 live births, with much higher rates seen in rural areas [7, 8]. Major causes of death include pneumonia, diarrhea, prematurity and congenital anomalies [7]. The Demographic and Health survey in Vietnam (2002) documented a $20 \%$ prevalence of symptoms compatible with acute respiratory infections (ARI), and an $11 \%$ prevalence of diarrhea in children under three years of age [9]. However, not all cases present to the health system in rural areas and many episodes are not captured by routine data sources; thus the burden of disease may be underreported. Information on maternal and early infant predictors of inpatient admission for these illnesses could greatly assist in the planning of prevention strategies, and early interventions could be targeted towards those most at risk. The primary objective of this study was to identify maternal and early infant factors associated with inpatient admission for suspected pneumonia or diarrheal illness during the first 6 months of life in Ha Nam province, Vietnam.

\section{Methods}

\section{Study area and population}

Ha Nam province is located in North Vietnam, approximately $60 \mathrm{~km}$ from Hanoi, in the Red River Delta. Ha Nam has an area of $852.2 \mathrm{~km}^{2}$, and a population of approximately 820,100 people with the majority of residents still working in subsistence agriculture [10, 11]. The main ethnic group populating this area is the Kinh, and the province is divided into 112 communes. It is a non-malarious area, with an average rainfall of 1,500 to $2,000 \mathrm{~mm}$ and annual average temperature of $23^{\circ}$ Celsius. The under 1 year mortality rate in the province is 12.5 per 1000 live births [11]. Health care is provided at the primary health care level through commune health stations (CHS) which are staffed by trained health workers. The team usually consists of a doctor, pharmacist, nurses and a traditional medicine practioner. The CHS provides care and treatment for common diseases and deliveries and carries out health promotion at the village level. Residents are entitled to free services at their local CHS but not at the CHS in other communes. The CHS has a responsibility to the District Health Officer and the Commune People's Committee, and receives technical guidance from the district hospitals.

\section{Study design and data collection}

A prospective cohort study design was used. The study was carried out in 104 communes and infants eligible for inclusion in the study were those born to women who had previously participated in a cluster randomised trial (Australian New Zealand Clinical Trials Registry:
ANZCTR 12610000944033) in the same province. In the original cluster randomised trial, allocation was based on communes, and all communes in the province, other than those in the main provincial town, were randomly assigned to one of three treatment groups. Those in the main provincial town were not included as part of the trial as antenatal services differed from those of the rest of the province, with most deliveries taking place at the provincial hospital. For the original cluster randomised trial, women received either [1] one tablet of iron-folic acid (IFA) taken daily $(60 \mathrm{mg}$ elemental iron $/ 0.4 \mathrm{mg}$ folic acid per tablet, 7 tablets per week); or [2] one capsule of IFA taken twice a week $(60 \mathrm{mg}$ elemental iron /1.5 mg folic acid per capsule; 2 capsules per week); or [12] one capsule of multiple micronutrients (MMN) taken twice a week $(60 \mathrm{mg}$ elemental iron/1.5 mg folic acid per capsule; 2 capsules per week, as well as a variation of the dose of the micronutrients in the UNICEF/WHO/UNU international multiple micronutrient preparation (UNIMMAP) supplement including zinc, iodine, copper, selenium, vitamin $\mathrm{A}$, thiamine, riboflavin, niacin, vitamin $\mathrm{B} 6$, vitamin $\mathrm{B} 12$, vitamin $\mathrm{C}$, vitamin D and vitamin E [13].

Inclusion criteria for the trial were: residence in trial communes, age $>16 \mathrm{y}$, confirmed pregnancy at $<16 \mathrm{wk}$ gestation, and registration with the commune health station. Women were excluded if they had a high-risk pregnancy-multi-fetal pregnancy (confirmed on palpation or ultrasound) or a significant medical condition-or if they had severe anemia (haemoglobin concentration $[\mathrm{Hb}]<80 \mathrm{~g} / \mathrm{l})$ at enrolment. Detailed information on the original cluster randomised trial and inclusion criteria have been reported elsewhere [14]. The trial was approved by the Melbourne Health Human Research Ethics Committee, and the Ha Nam Provincial Human Research Ethics Committee. Written informed consent was obtained from each participant.

Infant morbidity and inpatient admission was assessed at the 6-month post-partum visit to the commune health station, via a structured questionnaire using questions adapted from the World Health Organisation (WHO) Integrated Management of Childhood Illness [15] and modified for use in Vietnam. The primary outcome was inpatient admission for infant diarrheal illness or suspected pneumonia. Interviews were conducted by trained research assistants supervised by experienced Vietnamese and Australian researchers. Information on demographic, and maternal and early infant characteristics, including breast feeding, and maternal and infant nutritional status were collected at enrolment (mean gestational age 12.2 weeks), 32 weeks gestation, 6 weeks and 6 months post-partum. Information on maternal depression was collected at enrolment and 32 weeks gestation. Exclusive breast feeding was defined as- 'since 


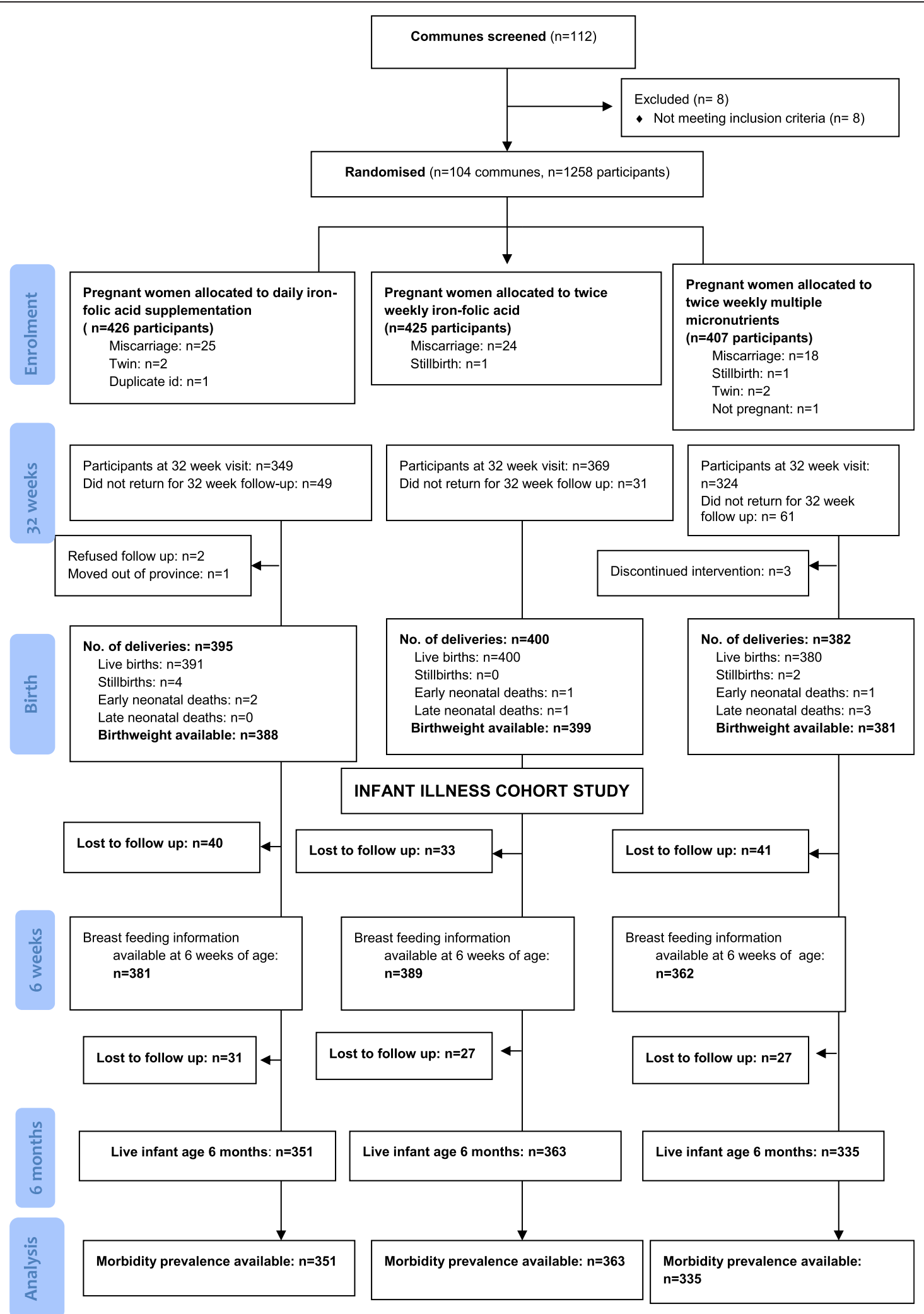

Fig. 1 Flow diagram 
Table 1 Characteristics of mothers at recruitment (baseline measurement) and characteristics of infants at delivery and 6 weeks in Ha Nam province, Vietnam $(n=1049)$

\begin{tabular}{|c|c|c|}
\hline & $\begin{array}{l}\text { Total study } \\
\text { population }\end{array}$ & \\
\hline Maternal characteristic & $\begin{array}{l}\text { Frequency, Mean } \\
\text { or Median }\end{array}$ & $\begin{array}{l}\text { (Percentage) } \\
\text { [Standard deviation] or } \\
\left\{25^{\text {th }}-75^{\text {th }} \text { percentile }\right\}\end{array}$ \\
\hline $\begin{array}{l}\text { Maternal age at enrolment } \\
\text { (years) }\end{array}$ & 26.7 & {$[4.9]$} \\
\hline$<20$ & 41 & (3.9) \\
\hline $20-24$ & 340 & $(32.4)$ \\
\hline $25-29$ & 426 & $(40.6)$ \\
\hline $30-34$ & 161 & $(15.4)$ \\
\hline$\geq 35$ & 81 & $(7.7)$ \\
\hline Maternal height & 153.6 & {$[4.7]$} \\
\hline $\begin{array}{l}<145 \mathrm{~cm} \text { (short maternal } \\
\text { stature) }\end{array}$ & 38 & (3.6) \\
\hline Maternal body mass index & 19.9 & {$[1.98]$} \\
\hline $\begin{array}{l}\text { Underweight } \\
\left(<18.5 \mathrm{~kg} / \mathrm{m}^{2}\right)\end{array}$ & 272 & $(26.0)$ \\
\hline Normal $\left(18.5-25 \mathrm{~kg} / \mathrm{m}^{2}\right)$ & 761 & $(72.6)$ \\
\hline Overweight (>25 kg/m²) & 15 & $(1.4)$ \\
\hline \multicolumn{3}{|l|}{ Educational level } \\
\hline Primary school & 160 & $(15.3)$ \\
\hline Secondary school & 705 & $(67.2)$ \\
\hline University/college & 184 & $(17.5)$ \\
\hline \multicolumn{3}{|l|}{ Occupation } \\
\hline Farmer/housewife & 561 & $(53.5)$ \\
\hline Factory worker/trader & 350 & (33.4) \\
\hline Government official/clerk & 138 & $(13.2)$ \\
\hline \multicolumn{3}{|l|}{ Main energy source } \\
\hline Gas & 849 & $(79.9)$ \\
\hline Firewood/Straw/Hay & 163 & $(15.4)$ \\
\hline Charcoal/coal & 30 & $(2.8)$ \\
\hline Electric & 20 & (1.9) \\
\hline \multicolumn{3}{|l|}{ Type of toilet } \\
\hline Flush toilet/septic tank & 716 & $(67.4)$ \\
\hline Compartment latrine & 173 & $(16.3)$ \\
\hline Pit latrine & 155 & $(14.6)$ \\
\hline None & 18 & $(1.7)$ \\
\hline \multicolumn{3}{|l|}{ Main water source } \\
\hline Rain water & 917 & $(86.4)$ \\
\hline Tap/piped water' & 87 & $(8.2)$ \\
\hline Well water/river water & 56 & (5.3) \\
\hline \multicolumn{3}{|l|}{ Gravidity } \\
\hline Primigravida & 328 & (31.3) \\
\hline Multigravida & 721 & $(68.7)$ \\
\hline
\end{tabular}

Table 1 Characteristics of mothers at recruitment (baseline measurement) and characteristics of infants at delivery and 6 weeks in Ha Nam province, Vietnam ( $n=1049)$ (Continued)

Supplements taken during

trial intervention

$\begin{array}{lll}\begin{array}{l}\text { Daily IFA supplements } \\ \text { Twice weekly IFA } \\ \text { supplements }\end{array} & 351 & (33.5) \\ \begin{array}{l}\text { MMN supplements } \\ \text { Micronutrient status in }\end{array} & 363 & (34.6) \\ \begin{array}{l}\text { late pregnancy } \\ \text { Haemoglobin (g/dL) }\end{array} & 12.3 & (31.9) \\ \text { Ferritin (ug/L) } & 28 & {[1.23]} \\ \text { B12 (pmol/L) } & 232 & \{17 \text { to } 42\} \\ \text { Folate (nmol/L) } & 28.7 & \{99 \text { to } 601\} \\ \text { lodine (ug/L) } & 52.9 & \{6.8 \text { to } 90\} \\ \end{array}$

Infant characteristics

Sex

Male 558

Birthweight (grams) $\quad 3157.6 \quad$ [396.6]

Low birth weight

(<2500 gms)

Gestational age (weeks) $39.1 \quad$ [2.0]

Preterm (<37 weeks) 166

Exclusive breast feeding 377

at 6 weeks of age

Use of dietary supplements 117

for the child in the first

6 months

birth, the child has only received breastmilk (with the exception of oral drops/syrups of vitamins/medicines) and has not been given any other liquids or solids (including water, traditional herbs).'

Maternal mental health was assessed using the Edinburgh Postnatal Depression Scale-Vietnam Validation (EPDS-V). The EPDS-V was translated from English, culturally verified and validated against psychiatrist-administered Structural Clinical Interviews for the Diagnostic and Statistical Manual of Mental Disorders, 4th Edition (DSM IV).

The cut-off point used to detect clinically significant symptoms in this setting was $\geq 4[14,16]$. Recurrent depression was defined as a positive EPDS score at enrolment and 32 weeks gestation. Details of the collection of other data used in this study has previously been published [14].

\section{Case definitions}

Suspected pneumonia was defined as any episode of cough or difficulty breathing since birth, and diarrheal infection as any episode of diarrhea (3 episodes of loose stools or bloody stools) since birth [15]. Diarrhea or 
Table 2 Maternal and early infant predictors of inpatient admission for suspected pneumonia during the first 6 months of life, Ha Nam province, Vietnam $(n=1049)$

\begin{tabular}{|c|c|c|c|c|c|c|}
\hline \multirow[b]{2}{*}{ Maternal Factors } & \multicolumn{3}{|c|}{ Univariable regression } & \multicolumn{3}{|c|}{ Multivariable regression $^{a}$} \\
\hline & Odds ratio & $95 \% \mathrm{Cl}$ & $P$ value & Odds ratio & $95 \% \mathrm{Cl}$ & $P$ value \\
\hline \multicolumn{7}{|l|}{ Demographic factors } \\
\hline Maternal age (years) & 0.96 & 0.91 to 1.01 & 0.06 & 0.95 & 0.89 to 1.00 & 0.06 \\
\hline \multicolumn{7}{|l|}{ Education } \\
\hline Primary & Reference & - & - & Reference & - & - \\
\hline Secondary & 0.97 & 0.53 to 1.78 & 0.92 & 0.95 & 0.48 to 1.91 & 089 \\
\hline University & 1.13 & 0.54 to 2.35 & 0.74 & 1.36 & 0.56 to 3.33 & 0.50 \\
\hline \multicolumn{7}{|l|}{ Gravidity } \\
\hline Primgravida & Reference & - & - & Reference & - & - \\
\hline Multigravida & 1.04 & 0.66 to 1.66 & 0.86 & 1.50 & 0.87 to 2.58 & 0.15 \\
\hline \multicolumn{7}{|l|}{ Main energy source } \\
\hline Gas & Reference & - & - & Reference & - & - \\
\hline Firewood/Straw/Hay & 0.85 & 0.45 to 1.61 & 0.62 & 0.88 & 0.45 to 1.72 & 0.70 \\
\hline Other & 0.72 & 0.22 to 2.39 & 0.60 & 0.82 & 0.18 to 3.68 & 0.79 \\
\hline \multicolumn{7}{|l|}{ Type of toilet } \\
\hline Flush toilet/septic tank & Reference & - & - & Reference & - & - \\
\hline Compartment latrine & 0.75 & 0.38 to 1.45 & 0.39 & 0.74 & 0.39 to 1.40 & 0.36 \\
\hline Pit latrine/none & 1.11 & 0.62 to 1.99 & 0.72 & 1.01 & 0.54 to 1.89 & 0.98 \\
\hline \multicolumn{7}{|l|}{ Main water source } \\
\hline Rain water & Reference & - & - & Reference & - & - \\
\hline Well water/river water & 2.22 & 1.04 to 4.73 & 0.04 & 2.67 & 1.05 to 6.77 & 0.04 \\
\hline Tap/piped water & 0.92 & 0.39 to 2.19 & 0.85 & 0.69 & 0.26 to 1.83 & 0.46 \\
\hline \multicolumn{7}{|l|}{ Nutritional and health status } \\
\hline Body mass index at enrolment $\left(\mathrm{kg} / \mathrm{m}^{2}\right)$ & 0.96 & 0.86 to 1.07 & 0.44 & & & \\
\hline Depression early pregnancy & 0.74 & 0.41 to 1.33 & 0.32 & & & \\
\hline Depression late pregnancy & 1.13 & 0.58 to 2.20 & 0.72 & & & \\
\hline \multicolumn{7}{|l|}{ Antenatal practices } \\
\hline Change of diet when pregnant & 1.39 & 0.81 to 2.38 & 0.23 & & & \\
\hline Meat intake during pregnancy (number of times per week) & 1.08 & 0.96 to 1.21 & 0.23 & & & \\
\hline \multicolumn{7}{|l|}{ Supplements taken during trial intervention } \\
\hline Daily IFA supplements & Reference & - & - & & & \\
\hline Twice weekly IFA supplements & 1.28 & 0.76 to 2.16 & 0.36 & 1.10 & 0.60 to 2.14 & 0.77 \\
\hline MMN supplements & 1.18 & 0.69 to 2.03 & 0.55 & 1.14 & 0.45 to 1.71 & 0.69 \\
\hline \multicolumn{7}{|l|}{ Micronutrient status in late pregnancy } \\
\hline Haemoglobin (g/dL) & 1.02 & 0.85 to 1.23 & 0.80 & & & \\
\hline Ferritin $\left(\log _{2} \mathrm{ug} / \mathrm{L}\right)^{\mathrm{b}}$ & 0.75 & 0.53 to 1.08 & 0.12 & & & \\
\hline $\mathrm{B} 12\left(\log _{2} \mathrm{pmol} / \mathrm{L}\right)^{\mathrm{b}}$ & 1.22 & 0.62 to 2.40 & 0.57 & & & \\
\hline Folate $\left(\log _{2} \mathrm{nmol} / \mathrm{L}\right)^{\mathrm{b}}$ & 0.73 & 0.41 to 1.29 & 0.28 & & & \\
\hline lodine $\left(\log _{2} u g / L\right)^{b}$ & 1.08 & 0.82 to 1.43 & 0.60 & & & \\
\hline \multicolumn{7}{|l|}{ Infant factors } \\
\hline Birthweight (per 100 grams) & 0.98 & 0.98 to 1.00 & 0.48 & & & \\
\hline Gestational age at delivery (weeks) & 0.88 & 0.80 to 0.98 & 0.02 & 0.92 & 0.82 to 1.04 & 0.18 \\
\hline
\end{tabular}


Table 2 Maternal and early infant predictors of inpatient admission for suspected pneumonia during the first 6 months of life, Ha Nam province, Vietnam ( $n=1049)$ (Continued)

\begin{tabular}{llllll}
\hline Male sex & 2.14 & 1.35 to 3.39 & 0.01 & 2.35 & 0.01 \\
Child care practices & & 0.44 & 0.25 to 0.75 & 0.01 & 0.39 \\
Exclusive breast feeding at six weeks of age & 0.40 to 1.38 & 0.34 & 0.20 to 0.75 \\
Use of dietary supplements for child in the first six months & 0.74 & 0.01 & \\
\hline
\end{tabular}

${ }^{a}$ Adjusted for maternal age, education, gravidity, trial intervention, infant sex, gestational age at delivery, type of toilet, water source, main energy source and other factors with statistically significant univariable associations with the outcome

${ }^{\mathrm{b}} \mathrm{Log}_{2}$ transformed-odds ratio represents a twofold change in ferritin, B12, folate or iodine

suspected pneumonia was classified as severe if the child required inpatient admission. All inpatient admissions between birth and 6 months were recorded. Inpatient admission was defined as an admission to any health care facility, that is, commune health centre or hospital during the first 6 months of life for suspected pneumonia or diarrheal illness.

\section{Statistical methods}

Data were analysed using Stata, Version 13 (StataCorp, College Station, TX, USA). Categorical data are presented as percentages with frequency, and continuous data are presented as mean and standard deviation (SD). Univariable logistic regression was initially performed to assess the association between maternal and early infant predictive factors, and inpatient admission for infant morbidity. Multivariable logistic regression models for maternal and early infant factors were then developed including factors with statistically significant univariable associations with the outcome, as well as confounding factors identified a priori (maternal age, education, gravidity, infant sex, gestational age, trial intervention, main water source, type of toilet and energy source). To account for clustering at the commune level, robust standard errors were calculated using the Huber-White Sandwich estimator.

\section{Results}

The 1258 women who were enrolled into the original cluster randomised trial delivered 1177 infants. Six were stillborn resulting in 1171 live born babies. Four early neonatal deaths and four late neonatal deaths occurred, and 114 were lost to follow up in the first 6 months of life. Thus a total of 1049 children were seen at 6 months of age (Fig. 1.)

Demographic and clinical characteristics of the infants are presented in Table 1. The majority of households used rain water $(86.5 \%), 66.7 \%$ had a flush toilet and gas $(79.6 \%)$ was the main source of fuel. At 6 weeks of age, one third of infants $(32.8 \%)$ were exclusively breast fed and less than $20 \%$ of infants had ever been exclusively breastfed during the first 6 months.

\section{Outpatient and hospital admission Suspected pneumonia}

Of the 1049 infants seen at 6 months of age, 407 (38.8\%) received outpatient care for suspected pneumonia and 92 $(8.8 \%)$ required inpatient admission. Maximum duration of inpatient care for suspected pneumonia was 22 days with a median of 7 days.

\section{Diarrheal illness}

Twenty percent of infants were seen as outpatients for diarrheal illness and $4 \%$ of infants required inpatient admission. Duration of inpatient admission ranged from 1 to 15 days (median 5 days). The majority (96\%) of infants with diarrhea received either medicine or an oral rehydration solution during their illness.

\section{Factors associated with inpatient admission Suspected pneumonia}

Table 2 presents maternal and early infant factors associated with inpatient admission for suspected pneumonia during the first 6 months of life. Exclusive breast feeding at 6 weeks of age (OR 0.39, $95 \%$ CI 0.20 to 0.75 ) reduced the odds of inpatient admission. Male infants (OR $2.35,95 \%$ CI 1.40 to 3.96 ) were twice as likely to require inpatient admission.

\section{Diarrheal illness}

Table 3 presents maternal and early infant factors associated with inpatient admission for diarrheal illness during the first 6 months of life. Exclusive breast feeding at 6 weeks of age reduced the odds of inpatient admission for diarrheal illness by more than $60 \%$ (OR 0.37, $95 \%$ CI 0.15 to 0.88$)$.

\section{Discussion}

To our knowledge, this is the largest study set in rural Vietnam to present a comprehensive overview of factors associated with inpatient admission for suspected pneumonia and diarrheal illness in early life. Our study demonstrates that the way an infant is fed has a significant effect on the development of severe morbidity in infancy. We demonstrated that exclusive breast feeding in early infancy significantly reduces the risk of inpatient admission for 
Table 3 Maternal and early infant predictors of inpatient admission for diarrheal illness during the first 6 months of life, Ha Nam province, Vietnam $(n=1049)$

\begin{tabular}{|c|c|c|c|c|c|c|}
\hline \multirow[b]{2}{*}{ Maternal Factors } & \multicolumn{3}{|c|}{ Univariable regression } & \multicolumn{3}{|c|}{ Multivariable regression $^{a}$} \\
\hline & Odds ratio & $95 \% \mathrm{Cl}$ & $P$ value & Odds ratio & $95 \% \mathrm{Cl}$ & $P$ value \\
\hline \multicolumn{7}{|l|}{ Demographic factors } \\
\hline Maternal age (years) & 0.94 & 0.88 to 1.01 & 0.09 & 0.92 & 0.83 to 1.01 & 0.09 \\
\hline \multicolumn{7}{|l|}{ Education } \\
\hline Primary & Reference & - & - & Reference & - & - \\
\hline Secondary & 1.22 & 0.50 to 2.97 & 0.52 & 1.08 & 0.40 to 2.88 & 0.88 \\
\hline University & 0.72 & 0.21 to 2.39 & 0.59 & 0.87 & 0.22 to 3.39 & 0.84 \\
\hline \multicolumn{7}{|l|}{ Gravidity } \\
\hline Primgravida & Reference & - & - & Reference & - & - \\
\hline Multigravida & 0.76 & 0.40 to 1.43 & 0.39 & 1.22 & 0.52 to 2.85 & 0.65 \\
\hline \multicolumn{7}{|l|}{ Main energy source } \\
\hline Gas & Reference & - & - & Reference & - & - \\
\hline Firewood/Straw/Hay & 1.44 & 0.67 to 3.08 & 0.35 & 1.30 & 0.55 to 3.08 & 0.55 \\
\hline Other & 0.53 & 0.07 to 3.97 & 0.54 & 0.59 & 0.07 to 4.74 & 0.50 \\
\hline \multicolumn{7}{|l|}{ Type of toilet } \\
\hline Flush toilet/septic tank & Reference & - & - & Reference & - & - \\
\hline Compartment latrine & 1.20 & 0.54 to 2.69 & 0.67 & 1.16 & 0.49 to 2.74 & 0.74 \\
\hline Pit latrine/none & 1.04 & 0.44 to 2.42 & 0.93 & 0.82 & 0.36 to 1.85 & 0.64 \\
\hline \multicolumn{7}{|l|}{ Main water source } \\
\hline Rain water & Reference & - & - & Reference & - & - \\
\hline Well water/river water & 1.81 & 0.62 to 5.27 & 0.28 & 1.43 & 0.50 to 4.11 & 0.50 \\
\hline Tap/piped water & 0.59 & 0.14 to 2.50 & 0.47 & 0.57 & 0.12 to 2.59 & 0.46 \\
\hline \multicolumn{7}{|l|}{ Nutritional and health status } \\
\hline Body mass index at enrolment $\left(\mathrm{kg} / \mathrm{m}^{2}\right)$ & 0.89 & 0.75 to 1.05 & 0.16 & & & \\
\hline Depression early pregnancy & 0.96 & 0.44 to 2.11 & 0.93 & & & \\
\hline Depression late pregnancy & 0.85 & 0.30 to 2.44 & 0.77 & & & \\
\hline \multicolumn{7}{|l|}{ Antenatal practices } \\
\hline Change of diet when pregnant & 0.75 & 0.39 to 1.46 & 0.40 & & & \\
\hline Meat intake during pregnancy (number of times per week) & 0.98 & 0.86 to 1.13 & 0.81 & & & \\
\hline \multicolumn{7}{|l|}{ Supplements taken during trial intervention } \\
\hline Daily IFA supplements & Reference & - & - & Reference & - & - \\
\hline Twice weekly IFA supplements & 1.44 & 0.67 to 3.08 & 0.35 & 0.72 & 0.34 to 1.52 & 0.39 \\
\hline MMN supplements & 0.53 & 0.07 to 3.97 & 0.54 & 0.93 & 0.40 to 2.15 & 0.86 \\
\hline \multicolumn{7}{|l|}{ Micronutrient status in late pregnancy } \\
\hline Haemoglobin (g/dL) & 1.12 & 0.86 to 1.46 & 0.41 & & & \\
\hline Ferritin $\left(\log _{2} \mathrm{ug} / \mathrm{L}\right)^{\mathrm{b}}$ & 0.76 & 0.46 to 1.25 & 0.28 & & & \\
\hline $\mathrm{B} 12\left(\log _{2} \mathrm{pmol} / \mathrm{L}\right)^{\mathrm{b}}$ & 1.05 & 0.40 to 2.79 & 0.92 & & & \\
\hline Folate $\left(\log _{2} \mathrm{nmol} / \mathrm{L}\right)^{\mathrm{b}}$ & 1.06 & 0.45 to 2.47 & 0.90 & & & \\
\hline lodine $\left(\log _{2} u g / L\right)^{b}$ & 0.90 & 0.61 to 1.32 & 0.59 & & & \\
\hline \multicolumn{7}{|l|}{ Infant Factors } \\
\hline Birthweight (per 100 grams) & 1.03 & 0.98 to 1.03 & 0.44 & & & \\
\hline Gestational age at delivery (weeks) & 1.02 & 0.87 to 1.20 & 0.78 & 1.05 & 0.93 to 1.19 & 0.46 \\
\hline
\end{tabular}


Table 3 Maternal and early infant predictors of inpatient admission for diarrheal illness during the first 6 months of life, Ha Nam province, Vietnam $(n=1049)$ (Continued)

\begin{tabular}{|c|c|c|c|c|c|c|}
\hline Male sex & 1.51 & 0.80 to 2.83 & 0.20 & 1.68 & 0.87 to 3.25 & 0.12 \\
\hline \multicolumn{7}{|l|}{ Child care practices } \\
\hline Exclusive breast feeding at six weeks of age & 0.46 & 0.21 to 1.04 & 0.05 & 0.37 & 0.15 to 0.88 & 0.03 \\
\hline Use of dietary supplements for child in the first six months & 1.23 & 0.43 to 3.52 & 0.69 & & & \\
\hline
\end{tabular}

${ }^{a}$ Adjusted for maternal age, education, gravidity, trial intervention, infant sex, gestational age at delivery, type of toilet, water source, main energy source and other factors with statistically significant univariable associations with the outcome

${ }^{\mathrm{b}} \mathrm{Log}_{2}$ transformed-odds ratio represents a twofold change in ferritin, B12, folate or iodine

suspected pneumonia or diarrheal illness during the first 6 months of life.

Our findings are consistent with those of previous studies demonstrating the importance of early infant feeding strategies. In a cohort study in the Philippines, Hengstermann et al. demonstrated that exclusively formula fed infants were more likely to be hospitalised for pneumonia and diarrhea, compared to exclusively breast fed infants [12]. Cesar et al. found that infants who were not breast fed were 17 times more likely to be admitted to hospital for pneumonia, compared to breast fed infants [17]. Hipgrave et al. identified increased rates of diarrhoea among children in households receiving infant formula compared with those who did not, [18] and Creek et al. identified that the majority of children hospitalized during a diarrheal outbreak were formula fed [19].

Other studies in developing countries have shown that infants who are formula fed are more likely to be hospitalised with diarrhoeal illness than infants who are exclusively breastfed, and that infants who are not breastfed are up to eight times more likely to die from diarrhoeal disease than breastfed infants [20-26].

Several mechanisms may be responsible for an infant becoming more vulnerable to severe infectious morbidity following the use of formula in early life. Formula may directly expose an infant to pathogens causing diarrhea either through contamination of formula, use of non-clean water sources during the preparation and cleaning of bottles, or inappropriate storage of formula [27-29]. In addition, formula also reduces the growth of beneficial bacteria such as Lactobacillus and Bifidobacteri, leading to a higher $\mathrm{pH}$ in the intestine and increased growth of pathogenic bacteria, making the intestinal environment of the child more susceptible to infection [30-32], as well as increasing intestinal permeability and bacterial translocation [33]. Our findings highlight the important immunological and protective benefits that breast feeding provides, in addition to the psychological, social, economic, and environmental benefits [34].

Prevalence of exclusive breast feeding was low in this population, with only one third of infants exclusively breast fed at 6 weeks of age and less than $20 \%$ having ever been exclusively breast fed during the first 6 months of life. Thu et al. have previously reported exclusive breast feeding in rural Vietnam at 3 months of age as $58 \%$ in boys and $65 \%$ in girls [35]. However a recent nutrition surveillance report in Vietnam showed that only $25 \%$ of infants were exclusively breast fed during the first 6 months of life [36]. Reasons for the low prevalence of exclusive breast feeding in Vietnam may include early return to work by mothers with grandparents caring for the infant, insufficient awareness of the benefits of breast feeding over formula feeding, lack of confidence and knowledge of mothers in breast feeding practices, maternal breast feeding misconceptions, family and media influences, social norms around breast feeding practices, and lack of support for women to overcome breast feeding problems [37-39].

The strengths of this study are the large sample size and randomisation of the mothers recruited for the original trial, as well as the comprehensive collection of antenatal and infant variables. Standardised definitions for diarrheal or suspected pneumonia were used to classify cases [15]. Limitations of this study are that the logistics of a large community-based study prevented the prospective collection of clinical and laboratory data at the time of each illness, and therefore factors associated with severe inpatient admission may have been underestimated. Despite these limitations, this is the largest study in rural Vietnam to provide a comprehensive overview of maternal and early life factors associated with severe morbidity in early life. This information will be useful for the development of targeted interventions for the prevention of severe infant morbidity in rural Vietnam.

\section{Conclusion}

Inpatient admission for suspected pneumonia or diarrheal illness in early infancy is reduced with exclusive breast feeding. There is an urgent need to develop strategies to address barriers to exclusive breast feeding in rural Vietnam, such as increased exclusive breast feeding promotional and educational activities at the primary health care level; improved support for mothers to exclusively breast feed from birth up until 6 months of age; eradication of common breast feeding myths; and strengthening of policies around promotion of exclusive breast feeding. 


\section{Abbreviations}

Cl: Confidence interval; CHS: Commune health station; (DSM IV): Diagnostic and statistical manual of mental disorders, 4th edition; Hb: Haemoglobin; OR: Odds ratio; SD: Standard deviation; UNIMMAP: UNICEF/WHO/UNU international multiple micronutrient preparation; WHO: World health organisation.

\section{Competing interests}

The authors declare that they have no competing interests.

\section{Authors' contributions}

$\mathrm{SH}, \mathrm{JAS}, \mathrm{TT}$, JF and BAB designed the study. SH, BAB and JAS prepared the manuscript. SH did statistical analysis. SH, TTH, TTh, NCK, DDT, and TDT participated in the collection and interpretation of the data; $\mathrm{SH}$ drafted the manuscript. All authors read and approved the final manuscript.

\section{Acknowledgement}

We thank the participants and health workers in Ha Nam province, the $\mathrm{Ha}$ Nam Provincial Centre of Preventive Medicine, Ministry of Health, RTCCD; Alfred Pathology; Beth Hilton-Thorp, and Christalla Hajisava.

\section{Author details}

'Department of Medicine, University of Melbourne, Doherty Institute, Parkville, VIC 3050, Australia. ${ }^{2}$ Research and Training Centre for Community Development, Hanoi, Vietnam. ${ }^{3}$ Centre for Epidemiology and Biostatistics, Melbourne School of Population and Global Health, University of Melbourne, Melbourne, VIC 3010, Australia. ${ }^{4}$ Provincial Centre of Preventive Medicine, Hanam Province, Vietnam. ${ }^{5}$ The Jean Hailes Research Unit, School of Public Health and Preventive Medicine, Monash University, Melbourne, VIC 3004, Australia. ${ }^{6}$ The Victorian Infectious Diseases Service, Royal Melbourne Hospital, Parkville, VIC 3052, Australia.

\section{Received: 3 February 2015 Accepted: 19 October 2015 Published online: 24 November 2015}

\section{References}

1. Bhutta ZA, Das JK, Rizvi A, Gaffey MF, Walker N, Horton S, et al. Evidence-based interventions for improvement of maternal and child nutrition: what can be done and at what cost? Lancet. 2013;382(9890):452-77. Epub 2013/06/12

2. Liu L, Johnson HL, Cousens S, Perin J, Scott S, Lawn JE, et al. Global, regional, and national causes of child mortality: an updated systematic analysis for 2010 with time trends since 2000. Lancet. 2012:379(9832):2151-61. Epub 2012/05/15

3. Checkley W, Buckley G, Gilman RH, Assis AM, Guerrant RL, Morris SS, et al. Multi-country analysis of the effects of diarrhoea on childhood stunting. Int J Epidemiol. 2008;37(4):816-30. Epub 2008/06/24

4. Walker SP, Wachs TD, Grantham-McGregor S, Black MM, Nelson CA, Huffman SL, et al. Inequality in early childhood: risk and protective factors for early child development. Lancet. 2011;378(9799):1325-38. Epub 2011/09/29.

5. Fischer Walker CL, Perin J, Aryee MJ, Boschi-Pinto C, Black RE. Diarrhea incidence in low- and middle-income countries in 1990 and 2010: a systematic review. BMC Public Health. 2012;12:220. Epub 2012/03/23.

6. Rudan I, El Arifeen S, Black RE, Campbell H. Childhood pneumonia and diarrhoea: setting our priorities right. Lancet Infect Dis. 2007;7(1):56-61. Epub 2006/12/22.

7. World Health Organisation. Viet Nam: health profile. Geneva: World Health Organisation; 2012. [cited 2014 March]; Available from: http://www.who.int/ gho/countries/vnm.pdf.

8. UN Inter-agency Group for Child Mortality Estimation. Under-five Mortality Estimates. New York: UNICEF; 2014. [cited 2014 November]; Available from: http://www.childmortality.org/.

9. National Committee for Population Family and Children Population and Family Health Project. Demographic and Health Survey 20022003. Available from: http://dhsprogram.com/pubs/pdf/FR139/FR139.pdf

10. Vietnam Academy of Social Science. Vietnam Poverty Update: Poverty and poverty reduction in Vietnam 1993-2004. Vietnamese Academy of Social Sciences: Hanoi, Vietnam; 2006.

11. General Statistics Office of Vietnam. Statistical Year Book of Vietnam. Hanoi: Statistical Publishing House; 2011.

12. Hengstermann S, Mantaring 3rd JB, Sobel HL, Borja VE, Basilio J, lellamo AD, et al. Formula feeding is associated with increased hospital admissions due to infections among infants younger than 6 months in Manila, Philippines. J Hum Lact. 2010:26(1):19-25.

13. United Nations Children's Fund. Composition of a Multimicronutrient Supplement to be used in Pilot Programmes among Pregnant Women in Developing Countries: Report of a UNICEF/WHO/UNU Workshop. UNICEF: New York; 1999

14. Hanieh S, Ha TT, Simpson JA, Casey GJ, Khuong NC, Thoang DD, et al. The effect of intermittent antenatal iron supplementation on maternal and infant outcomes in rural Viet Nam: a cluster randomised trial. PLoS Med. 2013;10(6), e1001470. Epub 2013/07/16.

15. WHO. Integrated Management of Childhood IIness. WHO: Geneva; 2008

16. Tran TD, Tran T, La B, Lee D, Rosenthal D, Fisher J. Screening for perinata common mental disorders in women in the north of Vietnam: a comparison of three psychometric instruments. J Affect Disord. 2011;133(1-2):281-93. Epub 2011/05/03.

17. Cesar JA, Victora CG, Barros FC, Santos IS, Flores JA. Impact of breast feeding on admission for pneumonia during postneonatal period in Brazil: nested case-control study. Bmj. 1999;318(7194):1316-20

18. Hipgrave DB, Assefa F, Winoto A, Sukotjo S. Donated breast milk substitutes and incidence of diarrhoea among infants and young children after the May 2006 earthquake in Yogyakarta and Central Java. Public Health Nutr. 2012;15(2):307-15. Epub 2011/03/24.

19. Creek TL, Kim A, Lu L, Bowen A, Masunge J, Arvelo W, et al. Hospitalization and mortality among primarily nonbreastfed children during a large outbreak of diarrhea and malnutrition in Botswana, 2006. J Acquir Immune Defic Syndr. 2010;53(1):14-9.

20. Bhutta ZA, Das JK, Walker N, Rizvi A, Campbell H, Rudan I, et al. Interventions to address deaths from childhood pneumonia and diarrhoea equitably: what works and at what cost? Lancet. 2013;381(9875):1417-29. Epub 2013/04/16

21. Dey SK, Chisti MJ, Das SK, Shaha CK, Ferdous F, Farzana FD, et al. Characteristics of diarrheal illnesses in non-breast fed infants attending a large urban diarrheal disease hospital in Bangladesh. PloS one. 2013:8(3), e58228. Epub 2013/03/23.

22. Abdel-Hafeez EH, Belal US, Abdellatif MZ, Naoi K, Norose K. Breast-feeding protects infantile diarrhea caused by intestinal protozoan infections. Korean J Parasitol. 2013:51(5):519-24. Epub 2013/12/12

23. Prameela KK, Vijaya LR. The importance of breastfeeding in rotaviral diarrhoeas. Malays J Nutr. 2012;18(1):103-11. Epub 2013/05/30.

24. Lopez-Alarcon M, Villalpando S, Fajardo A. Breast-feeding lowers the frequency and duration of acute respiratory infection and diarrhea in infants under six months of age. J Nutr. 1997;127(3):436-43. Epub 1997/03/01.

25. Arifeen S, Black RE, Antelman G, Baqui A, Caulfield L, Becker S. Exclusive breastfeeding reduces acute respiratory infection and diarrhea deaths among infants in Dhaka slums. Pediatrics. 2001;108(4), E67. Epub 2001/10/03.

26. Lauer JA, Betran AP, Barros AJ, de Onis M. Deaths and years of life lost due to suboptimal breast-feeding among children in the developing world: a global ecological risk assessment. Public Health Nutr. 2006;9(6):673-85.

27. Agostoni C, Axelsson I, Goulet O, Koletzko B, Michaelsen KF, Puntis JW, et al, Preparation and handling of powdered infant formula: a commentary by the ESPGHAN Committee on Nutrition. J Pediatr Gastroenterol Nutr. 2004;39(4):320-2.

28. Noriega FR, Kotloff KL, Martin MA, Schwalbe RS. Nosocomial bacteremia caused by Enterobacter sakazakiki and Leuconostoc mesenteroides resulting from extrinsic contamination of infant formula. Pediatr Infect Dis Js. 1990:9(6):447-9.

29. Lakshman R, Ogilvie D, Ong KK. Mothers' experiences of bottle-feeding: a systematic review of qualitative and quantitative studies. Arch Dis Child. 2009;94(8):596-601.

30. Rinne MM, Gueimonde M, Kalliomaki M, Hoppu U, Salminen SJ, Isolauri E. Similar bifidogenic effects of prebiotic-supplemented partially hydrolyzed infant formula and breastfeeding on infant gut microbiota. FEMS Immunol Med Microbiol. 2005:43(1):59-65.

31. Langhendries JP, Detry J, Van Hees J, Lamboray JM, Darimont J, Mozin MJ, et al. Effect of a fermented infant formula containing viable bifidobacteria on the fecal flora composition and $\mathrm{pH}$ of healthy full-term infants. J Pediatr Gastroenterol Nutr. 1995:21(2):177-81.

32. Gribble KD. Mechanisms behind breastmilk's protection against, and artificial baby milk's facilitation of, diarrhoeal illness. Breastfeed Rev. 2011;19(2):19-26.

33. Le Huerou-Luron I, Blat S, Boudry G. Breast- v. formula-feeding: impacts on the digestive tract and immediate and long-term health effects. Nutr Res Rev. 2010;23(1):23-36. Epub 2010/05/11

34. Prameela Jr KK, Mohamed AK. Breast milk immunoprotection and the common mucosal immune system: a review. Malays J Nutr. 2010;16(1):1-11. 
35. Thu HN, Eriksson B, Khanh TT, Petzold M, Bondjers G, Kim CN, et al. Breastfeeding practices in urban and rural Vietnam. BMC Public Health. 2012;12:964. Epub 2012/11/13.

36. National Institute of Nutrition, UNICEF. Nutrition Surveillance 2010: Vietnam Nutrition profile 2010. UNICEF: Hanoi; 2011.

37. Dibley MJ, Roy SK, Senarath U, Patel A, Tiwari K, Agho KE, et al. Acrosscountry comparisons of selected infant and young child feeding indicators and associated factors in four South Asian countries. Food Nutr Bull. 2010;31(2):366-75. Epub 2010/08/17.

38. Senarath U, Dibley MJ, Agho KE. Factors associated with nonexclusive breastfeeding in 5 east and southeast Asian countries: a multilevel analysis. J Hum Lact. 2010;26(3):248-57. Epub 2010/01/30.

39. Nguyen PH, Keithly SC, Nguyen NT, Nguyen TT, Tran LM, Hajeebhoy N. Prelacteal feeding practices in Vietnam: challenges and associated factors. BMC Public Health. 2013;13:932

\section{Submit your next manuscript to BioMed Central and take full advantage of:}

- Convenient online submission

- Thorough peer review

- No space constraints or color figure charges

- Immediate publication on acceptance

- Inclusion in PubMed, CAS, Scopus and Google Scholar

- Research which is freely available for redistribution 